\title{
Validation of Sea Surface Temperature from GCOM-C Satellite Using iQuam Datasets and MUR-SST in Indonesian Waters
}

\author{
Bambang Sukresno, Dinarika Jatisworo and Rizki Hanintyo \\ Institute for Marine Research and Observation
}

Received: $2020-03-29$

Accepted: 2021-04-06

Keywords:

Validation;

Sea surface temperature (SST);

GCOM-C;

iQuam;

MUR-SST

Correspondent email

bambang_sukresno@yahoo.com

\begin{abstract}
Sea surface temperature (SST) is an important variable in oceanography. One of the SST data can be obtained from the Global Observation Mission-Climate (GCOM-C) satellite. Therefore, this data needs to be validated before being applied in various fields. This study aimed to validate SST data from the GCOM-C satellite in the Indonesian Seas. Validation was performed using the data of Multi-sensor Ultra-high Resolution sea surface temperature (MUR-SST) and in situ sea surface temperature Quality Monitor (iQuam). The data used are the daily GCOM-C SST dataset from January to December 2018, as well as the daily dataset from MUR-SST and iQuam in the same period. The validation process was carried out using the three-way error analysis method. The results showed that the accuracy of the GCOM-C SST was $0.37^{\circ} \mathrm{C}$.
\end{abstract}

(92021 by the authors. Licensee Indonesian Journal of Geography, Indonesia.

This article is an open access article distributed under the terms and conditions of the Creative Commons

Attribution(CC BY NC) licensehttps://creativecommons.org/licenses/by-nc/4.0/.

\section{Introduction}

Indonesian Seas are affected by various oceanographic phenomena such as El Nino Southern Oscillation (ENSO) and Indian Ocean Dipole Mode (IOD) (Nur' utami \& Hidayat, 2016). During the El Nino and Positive IOD events, SST in the inner seas of Indonesia decreased, on the other hand during the La Nina and Negative IOD events, SST increased (Setiawan et al, 2019). The enhancement of chlorophyll-a concentration in Indonesian seas has a strong correlation with SST cooling which is coherent with ENSO and IOD (Setiawan et al, 2020). However, ENSO and IOD did not significantly influence the trends of SST in the Malacca Strait (Isa et al, 2020). Since sea surface temperature (SST) is sensitive to the interannual change, SST data with high accuracy is needed to investigate the effect of ENSO and IOD on the Indonesian Seas.

One of the satellite datasets that record SST is the Shikisai Global Change Observation Mission - Climate (GCOM-C). This satellite is part of the Global Change Observation Mission (GCOM), a global climate change program to fulfill the long-term observation mission carried out by the Japan Aerospace Exploration Agency (JAXA). The objectives of GCOM are for the monitoring of climate variability, water energy cycles, climate prediction, weather forecasting, fisheries, and supporting maritime agencies through the provision of near real-time data (Imaoka et al, 2010).

The use of GCOM-C satellites in the Indonesian Seas will contribute to the applications in various fields including climate variabilities, marine and fisheries. Therefore it is necessary to validate the data for the Indonesian Seas. To produce SST data that meets scientific specifications, validation using radiometer, buoy and other data needs to be conducted (Corlett et al, 2006). One of the comprehensive data for validating GCOM-C SST data is MUR-SST generated by the Multi-sensor Ultra-high Resolution (MUR) analysis project. This project was produced by the Group for High-Resolution Sea Surface Temperature (GHRSST) to provide daily high-resolution SST. High resolution cloud-free daily SST data is generated by combining an infrared sensor (IR) with a microwave sensor (MW). IR data has high spatial resolution but cannot penetrate the cloud, while the spatial resolution of MW data is relatively lower but can penetrate the cloud (Chin et al, 2013). Furthermore, in situ observation data is needed to determine the accuracy of the satellite SSTs.

The accuracy of SST from satellite data is one of the most important factors for climate and ocean analysis. In a short temporal scale analysis and narrow spatial scale, high SST accuracy is needed. The relatively small difference in accuracy will significantly influence the results of the analysis (Huang et al, 2017). Hausfather et al (2017), further stated the importance of SST dataset accuracy in various applications, especially in observing global warming and climate prediction.

One of the representative data is the in situ sea surface temperature Quality Monitor (iQuam), which is managed by the National Aeronautics and Space Administration (NASA) since 2009 and has been widely used in various SST analyzes and SST validation of satellite data. In situ observation data consisted of various data sources such as a ship, drifter, ARGO Float, Coastal mooring and Tropical mooring (Xu and Ignatov, 2016).

Traditional validation of SST was performed through comparison between satellite data and in situ measurement (Corlett et al, 2006). Comparative analysis has weaknesses due to the error of each data. In situ data have errors as a 
result of the variability of the depth measurement, while satellite data has errors as a result of cloud contamination. By using three-way error analysis, the error of each data has been considered, so that the satellite data validation gets higher (O'Carroll et al, 2008). The same method was carried out by $\mathrm{Xu}$ and Ignatov (2016), who validated SST data from National Oceanic and Atmospheric Administration (NOAA) and Envisat Advanced Along Track Scanning Radiometer (AATSR) satellites using iQuam in situ data. For the Indonesian Seas area, previously Sukresno et al (2018) used this method to validate the Himawari-8 satellite data using in situ data from the Indonesian buoy. Three-way error analysis has also been used to validate diurnal amplitude of SST using in situ mooring buoy data and Satellite SST of Himawari-8 and Geostationary Operational Environmental Satellite (GOES) (Wirasatriya et al, 2020).

In this study, we aimed: (1) To validate GCOM-C SST dataset in Indonesian Seas; (2) To evaluate the use of iQuam dataset for SST validation; and (3) to evaluate the use of three -way error analysis in the validation of the GCOM-C SST dataset.

\section{Method \\ GCOM-C}

The "SHIKISAI" GCOM-C satellite was launched on December 23, 2017, by the Japan Aerospace Exploration Agency (JAXA). The SST algorithm is developed using an infrared thermal channel (TIR), T1 at a wavelength of 10.8 $\mu \mathrm{m}$ and $\mathrm{T} 2$ at a wavelength of $12.0 \mu \mathrm{m}$ (Imaoka et al, 2010). SST preparation of the SGLI sensor was conducted by applying the SST determination and cloud masking stages (Kurihara, 2018). The GCOM-C dataset used in this study is daily level 3 data from January to December 2018 with a spatial resolution of $1 / 24^{\circ}$. An example of ascending data on
January 23, 2018, is presented in Figure.2.1 while descending data are presented in Figure.2.2. GCOM-C datasets can be downloaded via the Globe Portal System http:// gportal.jaxa.jp/gpr/.

\section{MUR-SST}

MUR-SST is generated by applying the Multi-Resolution Variational Analysis (MRVA) algorithm with input data from various sensors. The data used consists of IR and MW such as Advanced Very High-Resolution Radiometer (AVHRR), Moderate Resolution Imaging Spectroradiometer (MODIS), Advanced Along-Track Scanning Radiometer (AATSR), Advanced Microwave Scanning Radiometer Earth Observing System (AMSRE), Tropical Rainfall Measuring Mission Microwave Imager (TMI), Geostationary Operational Environmental Satellite (GOES) Imager and Spinning Enhanced Visible and Infrared Imager (SEVIRI). The MUR-SST dataset used in this study is daily data from January to December 2018 with a spatial resolution of $0.01^{\circ}$. MUR-SST datasets can be downloaded via the website: https://coastwatch.pfeg.noaa.gov/erddap/search/index.html? page $=1 \&$ itemsPerPage $=1000 \&$ searchFor $=$ mursst

\section{iQuam}

Iquam is in situ dataset, that developed by the Center for Satellite Application and Research (STAR) of the National Oceanic and Atmospheric Administration (NOAA). The data is obtained from the ship, drifter, ARGO Float and Tropical mooring data. The data has been processed with strict quality control (QC) so that in situ data obtained are reliable as presented in Figure 2.3. This study used iQuam dataset obtained from ship measurement from January to December 2018. iQuam datasets can be downloaded via NOAA website in the URL:

https://www.star.nesdis.noaa.gov/sod/sst/iquam/data.html

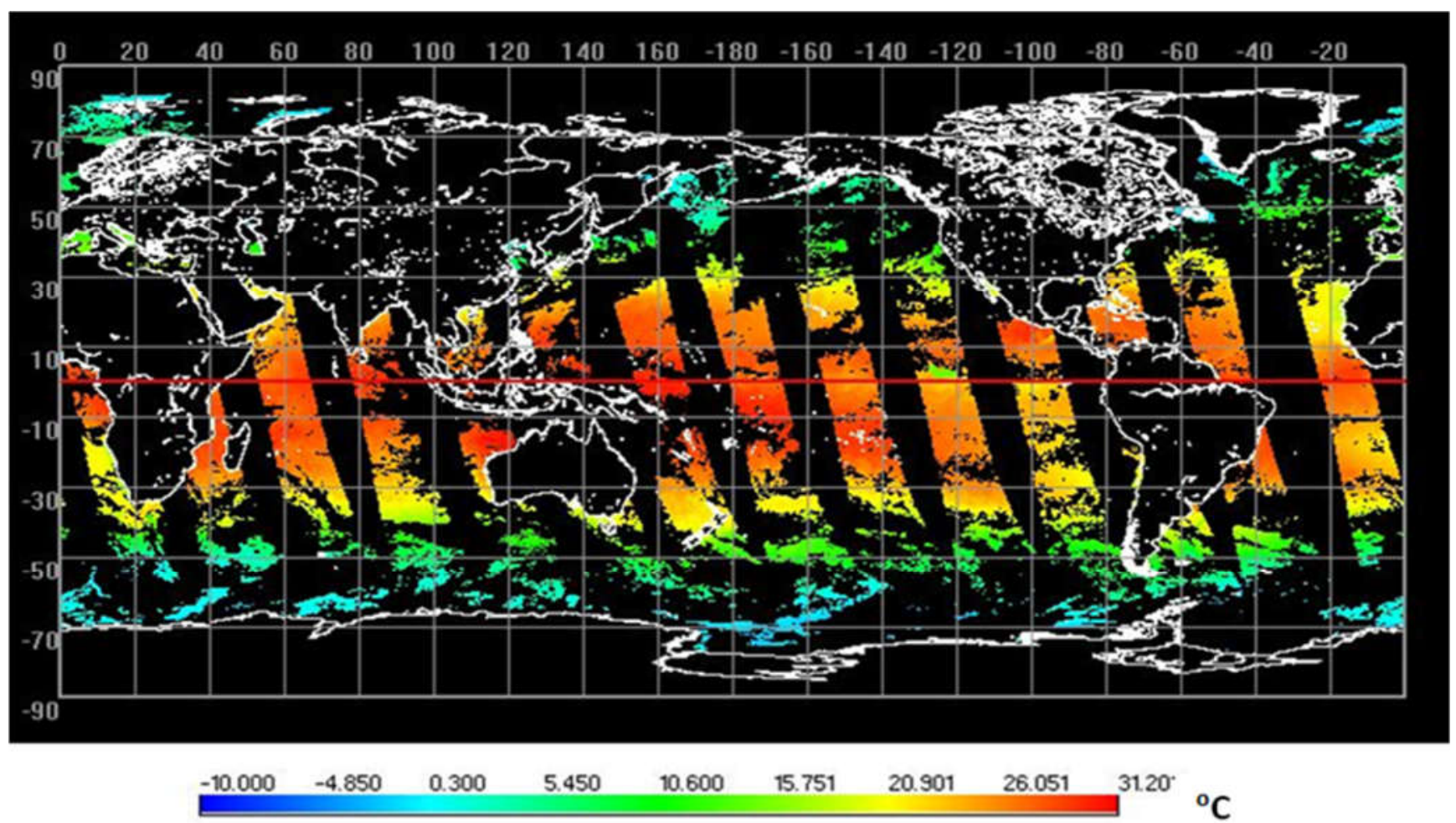

Figure 2.1. Global GCOM-C satellite data on January 23, 2018 in ascending mode 


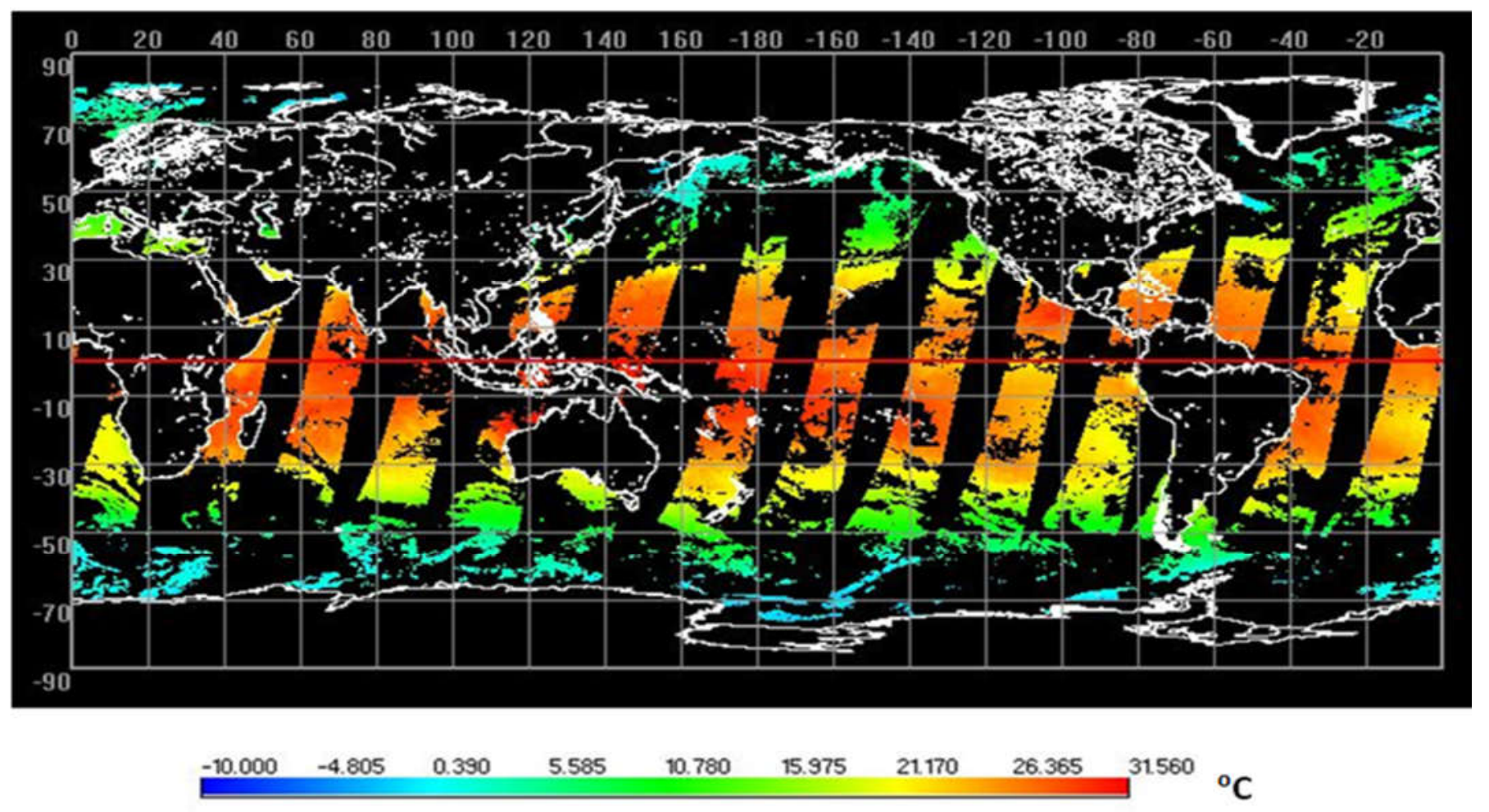

Figure 2.2. Global GCOM-C satellite data on January 23, 2018 in descending mode

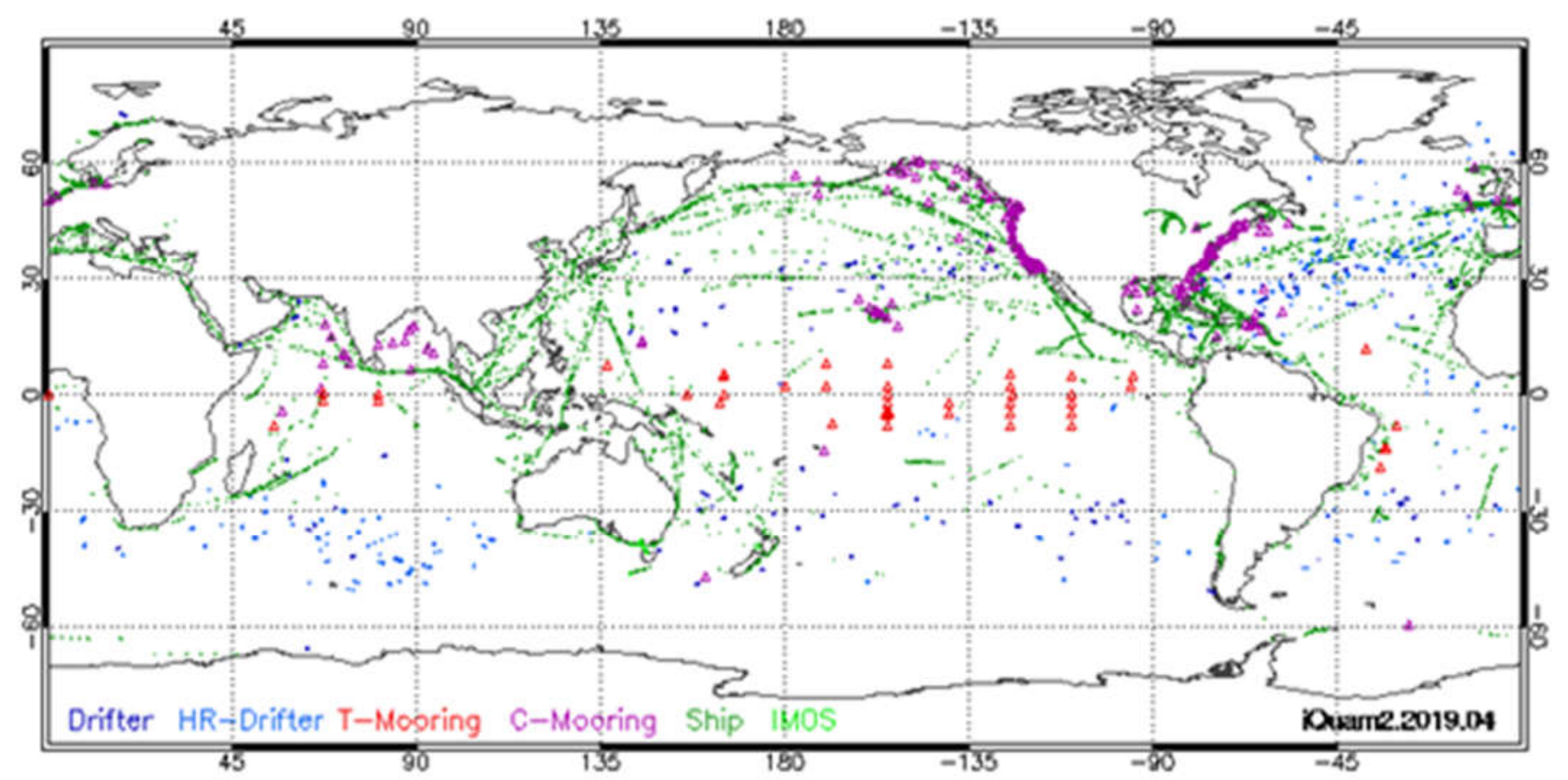

Figure 2.3. iQuam data distribution from various platforms

Source: https://www.star.nesdis.noaa.gov/sod/sst/iquam/

\section{Collocation Criteria}

GCOM-C data extraction was carried out according to the iQuam in situ data location. The collocation process between GCOM-C and iQuam was conducted on the same acquisition day. GCOM-C datasets are strongly influenced by cloud cover, only at the cloud-free location, the SST data can be extracted. Therefore data in cloud-covered locations are not used in further analysis. The filtering process is performed to discard cloud-covered data.
MUR-SST was collocated with iQuam datasets on the same acquisition day. MUR-SST datasets are relatively undisturbed by cloud cover due to the process of combining IR data with microwave data that can penetrate the cloud. The algorithm used to generate SST from MUR-SST has considered skin and sub-skin SST so that the products represent the foundation SST (JAXA, 2018; Chin et al, 2013). The dataset can be overlaid directly with iQuam 
datasets to get data collocation. Quality flag status of iQuam data ranges from lowest bit 0 to highest bit 15 . Lowest bit $0-1$ reported overall quality, bit from 2 - 3 reported all duplicate check, bit 4 reported Track Check and Geolocation Check, bit 5 reported SST spike check, bit 6 reported ID check, bit 7 reported number of buddies check, the rest bit 8-15 were Scaled Probability of Gross Error (Xu and Ignatov, 2014). In this study, iQuam with quality levels 4 and 5 was used. The collocation process between GCOM-C and MUR-SST is carried out on the same acquisition day and each pixel where the iQuam data is located.

\section{Three-Way Error Analysis}

After data extraction and collocation, the datasets were analyzed by using the 3-way error method following $\mathrm{O}$ ' Carroll et al (2008). Extraction and collocation were performed throughout daily SST from January to December 2018. The accuracy of each observation type is based on the calculation of the SST variance of difference. The equation of three-way error analysis is as follow:

$$
\begin{aligned}
& \sigma_{G}=\sqrt{0.5\left(V_{G M}+V_{G i}-V_{M i}\right)} \\
& \sigma_{M}=\sqrt{0.5\left(V_{G M}+V_{M i}-V_{G i}\right)} \\
& \sigma_{i}=\sqrt{0.5\left(V_{G i}+V_{M i}-V_{G m}\right)}
\end{aligned}
$$

Where $\sigma$ is the error variance representing the accuracy of data, $V$ is the variance of difference SST, $G, M, i$ are GCOMC, MUR-SST and iQuam respectively.

\section{Results And Discussion}

GCOM-C satellite measures the territory of Indonesia in several swathes so that the entire area is covered. Figure 3.1 shows the example of GCOM-C satellite SST satellite on April 2, 2018. SST data along the track of satellite is not fully covered, because IR wavelengths cannot penetrate the cloud.

MUR-SST datasets, which are an integration of various satellite data both of IR and MW wavelengths, provide daily SST data. The example of MUR-SST data that relatively cloud -free is presented in Figure 3.2.

IQuam datasets used in SST validation have an evenly spatial distribution across Indonesian Seas. The example of iQuam data in January 2018 is presented in Figure. 3.3. IQuam datasets are presented from the Indian Ocean to the Pacific Ocean and the inner seas of Indonesia.

\section{Initial comparison}

The process of collocation was conducted only in the Indonesian Seas. From the collocation process, a total of 107,346 matchups dataset between iQuam and MUR-SST were obtained. However, only 13.379 matchups dataset between iQuam and GCOM-C were obtained due to cloud coverage. Likewise, collocation between GCOM-C and MURSST only obtain 13.379 matchups datasets.
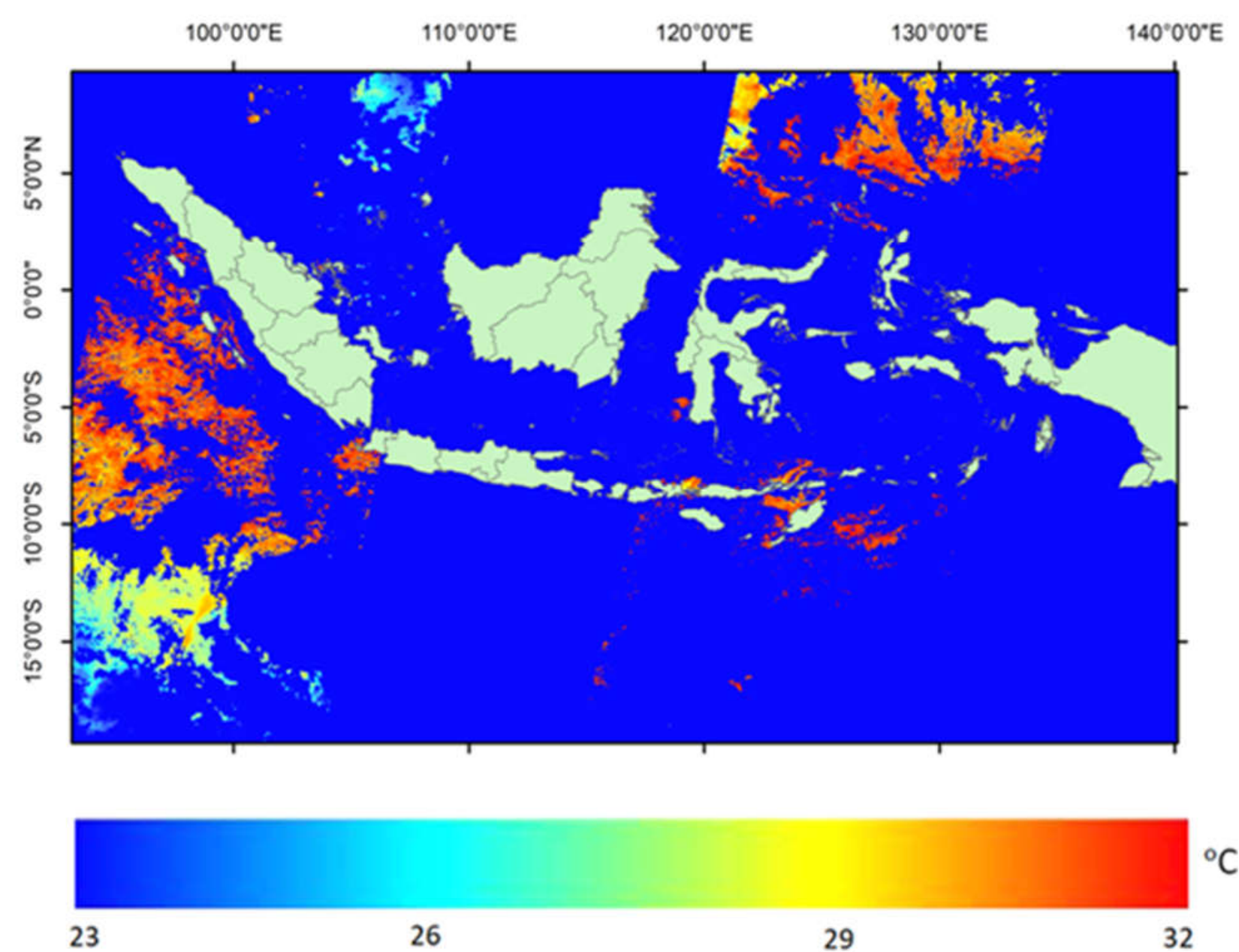

Figure 3.1. SST of GCOM-C satellite in April 2, 2018 


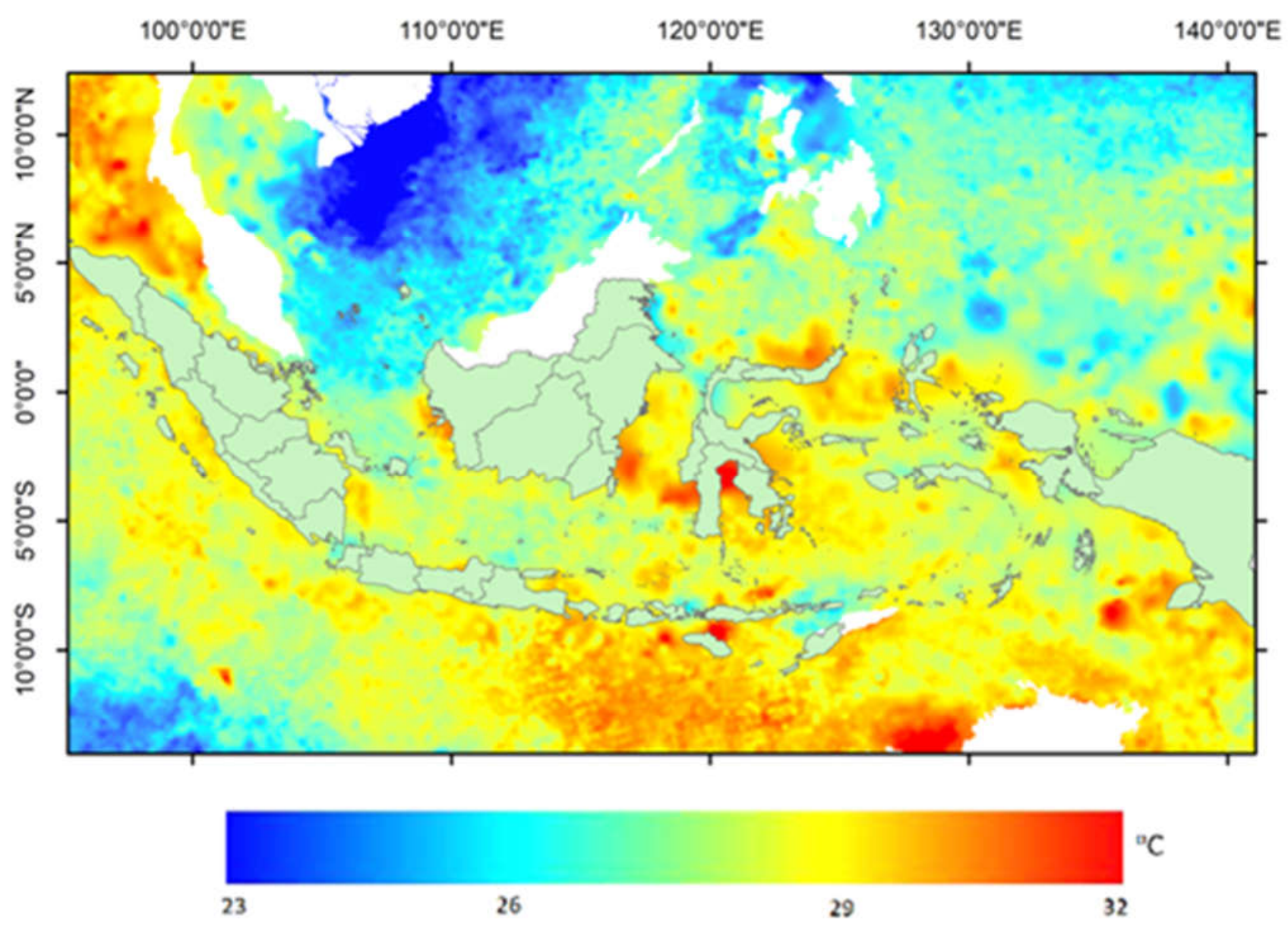

Figure 3.2. AOI of MUR SST in April 2, 2018

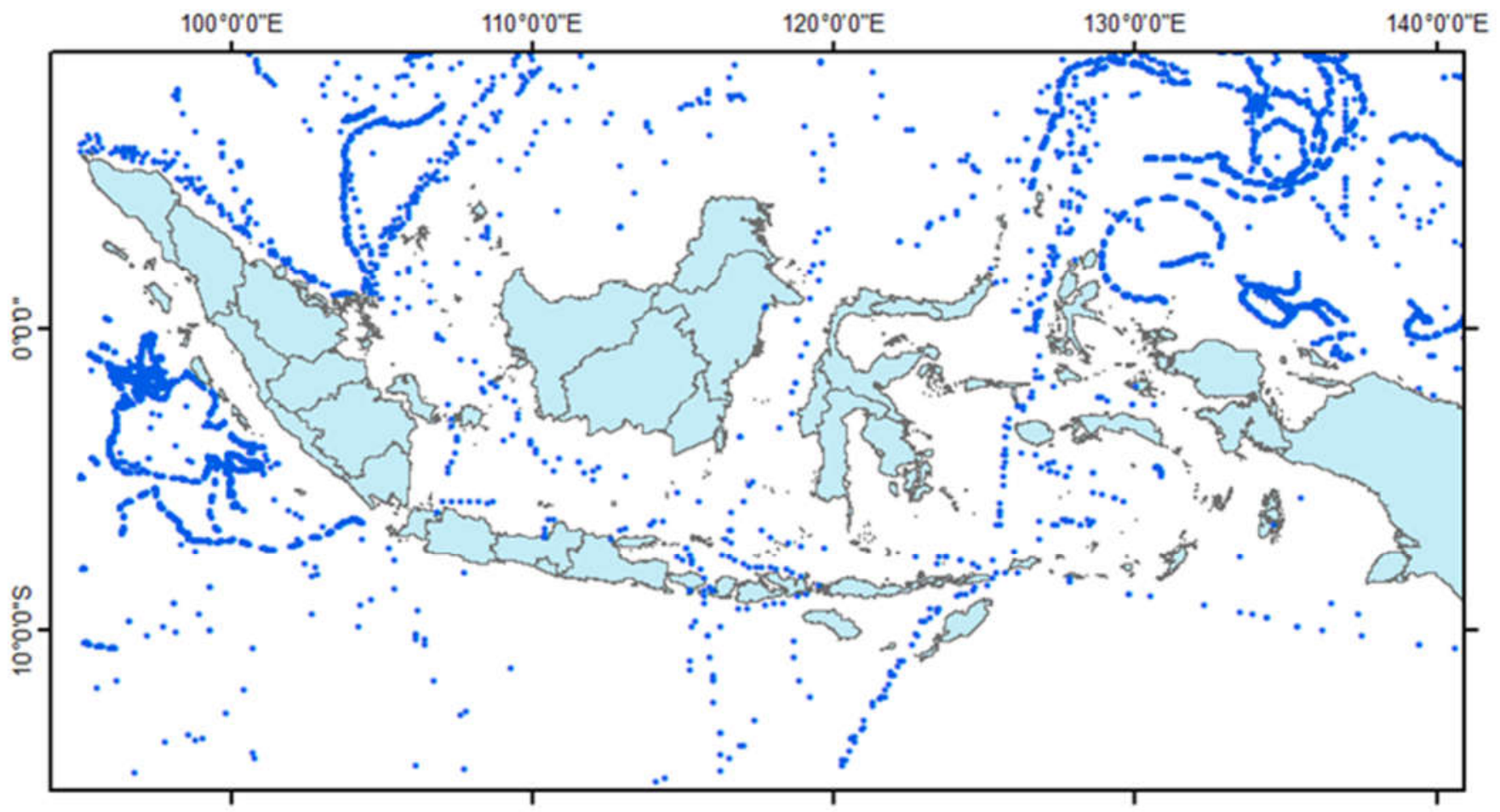

Figure 3.3. Spatial distribution of iQuam dataset from various platforms in January 2018 

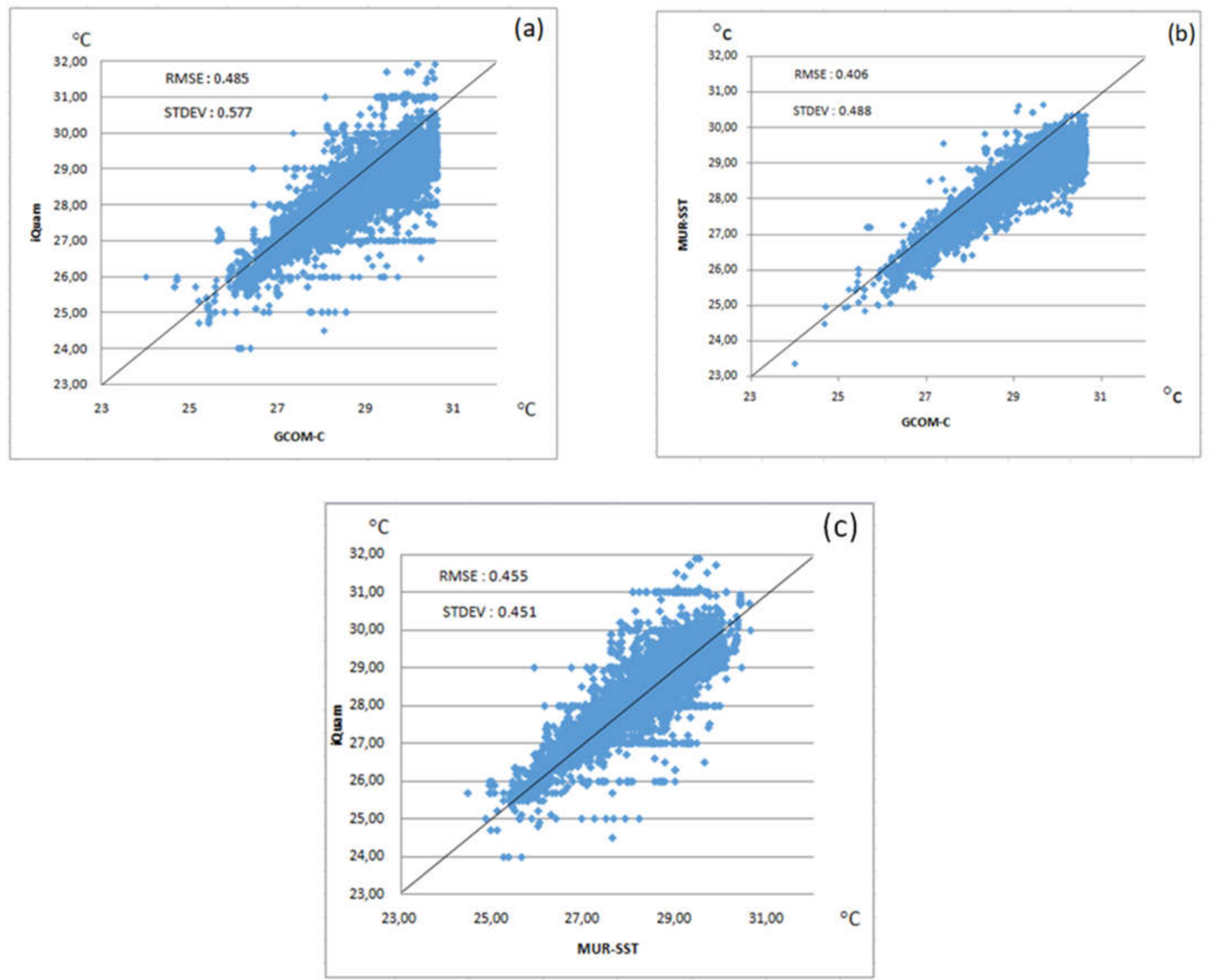

Figure 3.4. RMSE between GCOM-C satellite data with iQuam (a), GCOM-C with MUR-SST (b) and MUR-SST with iQuam (c)

Table 3.1 Standard Deviation and RMSE of GCOM-C, MUR-SST and iQuam

\begin{tabular}{lll}
\hline & Standard Dev & RMSE \\
\hline 1. GCOM-C with MUR-SST & 0.488 & 0.406 \\
2. GCOM-C with iQuam & 0.577 & 0.485 \\
3. MUR-SST with iQuam & 0.451 & 0.455 \\
\hline
\end{tabular}

Table 3.3. Variance of Difference of SST data

\begin{tabular}{llll}
\hline & GCOM-C & MUR-SST & iQuam \\
\hline 1. Max & 30.63 & 30.64 & 31.90 \\
2. Min & 24.67 & 24.47 & 24.00 \\
3. Average & 28.41 & 28.41 & 28.47 \\
\hline
\end{tabular}

Table 3.2. Data Characteristics of GCOM-C, MUR-SST and iQuam

\begin{tabular}{llll}
\hline & GCOM-C & MUR-SST & iQuam \\
\hline 1. Max & 30.63 & 30.64 & 31.90 \\
2. Min & 24.67 & 24.47 & 24.00 \\
3. Average & 28.41 & 28.41 & 28.47 \\
\hline
\end{tabular}

Table 3.4. Error analysis result of SST data

\begin{tabular}{lc}
\hline SST data & Variance of Difference \\
\hline 1. GCOM-C with MUR-SST & 0.24 \\
2. GCOM-C with iQuam & 0.17 \\
3. MUR-SST with iQuam & 0.21 \\
\hline
\end{tabular}


Initial comparison of GCOM-C, MUR-SST satellite datasets and iQuam in situ dataset were performed by displaying the scatter plot of the three data. The root means squared error (RMSE) analysis was performed as presented in Figure 3.4 .

Standard Deviation and RMSE between GCOM-C with MUR-SST, GCOM-C with iQuam and iQuam with MURSST can be seen in Table 3.1

The characteristics of GCOM-C, MUR-SST and iQuam datasets can be seen in table 3.2. The values of maximum, minimum and average of each data show relatively similar values.

IQuam datasets have the highest SST maximum characteristics compared to other data that is equal to $31.90^{\circ} \mathrm{C}$. GCOM-C satellite datasets have the lowest maximum value of $30.63^{\circ} \mathrm{C}$, while the lowest minimum value is presented by iQuam datasets which is $24.00^{\circ} \mathrm{C}$. In general, the average SST of each data is not much different where the GCOM-C, MUR-SST and iQuam datasets have an average of $28.41^{\circ} \mathrm{C}, 28.41^{\circ} \mathrm{C}$ and $28.47^{\circ} \mathrm{C}$, respectively.

The value of each variance can be seen in the table 3.3. The largest SST variance value was found in the comparison between GCOM-C and MUR-SST is equal to 0.24 . On the other hand, the smallest SST variance value is presented by the comparison between GCOM-C datasets with iQuam which is 0.17 , while the SST variance between MUR-SST and iQuam is 0.21 .

\section{Three-way error analysis}

Three-way error analysis of SST was analyzed based on the variance of SST differences between GCOM-C, MURSST and iQuam datasets. The result shows the accuracy of each data as displayed in Table 3.4 .

Based on the analysis results as in table 3.4, it appears that the smallest SST error value is found in the iQuam datasets which are equal to $0.26^{\circ} \mathrm{C}$, this is possible because the SST measurements are carried out directly where the temperature sensor used touches the body of water directly. Unlike the case with GCOM-C datasets and MUR-SST datasets, SST data are obtained from sensors that do not come into direct contact with water bodies. In the measurement process, GCOM-C and MUR-SST datasets are disturbed by the presence of atmospheric layers which bias the measured SST values.

Compared to other methods, three-way error analysis showed a higher accuracy, where GCOM-C SST errors are relatively small about $0.37^{\circ} \mathrm{C}$ while using other methods as conducted by JAXA (2018) using the RMSE method, the error value of GCOM-C SST was $0.8^{\circ} \mathrm{C}$. Hori et al (2018), also applied the RMSE method and displayed the scatter plot between GCOM-C datasets and iQuam datasets. From the analysis, it is known that the RMSE of the data is $0.82^{\circ} \mathrm{C}$. The advantages of the three-way error analysis method for validating satellite data are also stated by Gentemann (2014), who analyzed SST data from MODIS and AMSR-E satellites and obtained a higher accuracy.

\section{Conclusion}

Three-way error analysis showed a higher accuracy compared to the RMSE method. Validation of SST of GCOM -C dataset using three-way error analysis results in high accuracy of about $0.37^{\circ} \mathrm{C}$ while using RMSE method, the accuracy of GCOM-C dataset is about $0.48^{\circ} \mathrm{C}$. In situ iQuam datasets are spread evenly in the Indonesian Seas. The availability of in situ data provides its advantages in the collocation stage as pre-processing data before accuracy analysis.

\section{Acknowledgments}

SST datasets of the GCOM-C satellite were provided by Japan Aerospace Exploration Agency. The GHRSST MURSST data were obtained from the NASA EOSDIS Physical Oceanography Distributed Active Archive Center (PODAAC) at the Jet Propulsion Laboratory, Pasadena, CA. iQuam in situ datasets were developed by NOAA Center for Satellite Application and Research (STAR).

\section{Reference}

Chin, T.M., Vazquez, J. and Armstrong, E., (2013). Algorithm theoretical basis document: a multi-scale, high-resolution analysis of global sea surface temperature, vers. 1.3. Jet Propulsion Laboratory, Pasadena.

Corlett, G. K., Barton, I. J., Donlon, C. J., Edwards, M. C., Good, S. A., Horrocks, L. A., \& Noyes, E. J. (2006). The accuracy of SST retrievals from AATSR: An initial assessment through geophysical validation against in situ radiometers, buoys and other SST data sets. Advances in Space Research, 37(4), 764-769.

Gentemann, C.L., (2014). Three-way validation of MODIS and AMSR-E sea surface temperatures. Journal of Geophysical Research: Oceans, 119(4), pp.2583-2598.

Hausfather, Z., Cowtan, K., Clarke, D.C., Jacobs, P., Richardson, M. and Rohde, R., (2017). Assessing recent warming using instrumentally homogeneous sea surface temperature records. Science advances, 3(1), p.e1601207.

Hori, M., Murakami, H., Miyazaki, R., Honda, Y., Nasahara, K., Kajiwara, K., Nakajima, T.Y., Irie, H., Toratani, M., Hirawake, T. and Aoki, T., (2018). GCOM-C Data Validation Plan for Land, Atmosphere, Ocean, and Cryosphere. Transactions Of The Japan Society For Aeronautical And Space Sciences, Aerospace Technology Japan, 16(3), Pp.218-223.

Huang, B., Thorne, P.W., Banzon, V.F., Boyer, T., Chepurin, G., Lawrimore, J.H., Menne, M.J., Smith, T.M., Vose, R.S. and Zhang, H.M., (2017). Extended reconstructed sea surface temperature, version 5 (ERSSTv5): upgrades, validations, and intercomparisons. Journal of Climate, 30(20), pp.8179-8205.

Imaoka, K., Kachi, M., Fujii, H., Murakami, H., Hori, M., Ono, A., Igarashi, T., Nakagawa, K., Oki, T., Honda, Y. and Shimoda, H., (2010). Global Change Observation Mission (GCOM) for monitoring carbon, water cycles, and climate change. Proceedings of the IEEE, 98(5), pp.717-734.

Isa, N.S., Akhir, M.F., Kok, P.H., Daud, N.R., Khalil, I. and Roseli, N.H., 2020. Spatial and temporal variability of sea surface temperature during El-Niño Southern Oscillation and Indian Ocean Dipole in the Strait of Malacca and Andaman Sea. Regional Studies in Marine Science, 39, p.101402.

JAXA . (2018). GCOM-C “SHIKISAI” Data Users Handbook First Edition.

Kurihara, Y., (2018). ATBD for GCOM-C/SGLI Sea Surface Temperature (SST)

Nur'utami, M.N. and Hidayat, R., (2016). Influences of IOD and ENSO to Indonesian rainfall variability: role of atmosphereocean interaction in the Indo-Pacific sector. Procedia Environmental Sciences, 33, pp.196-203.

O'Carroll, A.G., Eyre, J.R. and Saunders, R.W., (2008). Three-way error analysis between AATSR, AMSR-E, and in situ sea surface temperature observations. Journal of Atmospheric and Oceanic Technology, 25(7), pp.1197-1207.

Setiawan, R.Y., Wirasatriya, A., Hernawan, U., Leung, S. and Iskandar, I., 2020. Spatio-temporal variability of surface chlorophyll-a in the Halmahera Sea and its relation to ENSO 
and the Indian Ocean Dipole. International Journal of Remote Sensing, 41(1), pp.284-299.

Setiawan, R.Y., Setyobudi, E., Wirasatriya, A., Muttaqin, A.S. and Maslukah, L., 2019. The Influence of Seasonal and Interannual Variability on Surface Chlorophyll-a Off the Western Lesser Sunda Islands. IEEE Journal of Selected Topics in Applied Earth Observations and Remote Sensing, 12(11), pp.4191-4197.

Sukresno, B., Hanintyo, R., Kusuma, D.W., Jatisworo, D. and Murdimanto, A., (2018). Three-way error analysis of sea surface temperature (SST) between HIMAWARI-8, buoy, and mur SST in SAVU Sea. International Journal of Remote Sensing and Earth Sciences (IJReSES), 15(1), pp.25-36.

Wirasatriya, A., Hosoda, K., Setiawan, J.D. and Susanto, R.D., 2020. Variability of Diurnal Sea Surface Temperature during Short Term and High SST Event in the Western Equatorial Pacific as Revealed by Satellite Data. Remote Sensing, 12(19), p.3230.

$\mathrm{Xu}, \mathrm{F}$. and Ignatov, A., (2016). Error characterization in iQuam SSTs using triple collocations with satellite measurements. Geophysical Research Letters, 43(20), pp.10-826.

$\mathrm{Xu}, \mathrm{F}$. and Ignatov, A., (2014). In situ SST quality monitor (i Quam). Journal of Atmospheric and Oceanic Technology, 31(1), pp.164-180. 